Original Article

\title{
Variations in clinical estimates of tumor volume regression parameters and time factor during external radiotherapy in cancer cervix: does it mimic the linear-quadratic model of cell survival?
}

\author{
Datta NR, Rajkumar A, Basu R \\ Department of Radiotherapy, Sanjay Gandhi Postgraduate Institute of Medical Sciences, Lucknow, \\ India
}

Correspondence to: Prof. N. R. Datta, E-mail: nrdatta@sgpgi.ac.in

\begin{abstract}
BACKGROUND: Tumor regression parameters and time factor during external radiotherapy (EXTRT) are of paramount importance. AIMS: To quantify the parameters of tumor regression and time factor during EXTRT in cancer cervix. SETTINGS AND DESIGN: Patients, treated solely with radiotherapy and enrolled for other prospective studies having weekly tumor regressions recorded were considered. MATERIALS AND METHODS: Seventy-seven patients received 50Gy of EXTRT followed by intracavitary brachytherapy. Loco-regional regressions were assessed clinically and regression fraction (RF) was represented as $R F=c+a_{1} D+a_{2} D^{2}-a_{3} T$, with $c$, $D$ and $T$ as constant, cumulative EXTRT dose and treatment time respectively. STATISTICAL ANALYSIS USED: Step wise linear regression was performed for RF. Scatter plots were fitted using linear-quadratic fit. RESULTS: Coefficients of parameters $D, D^{2}$ and T were computed for various dose intervals, namely 0-20 Gy, 0-30 Gy, 0-40 Gy and 0-50 Gy. At 0-20 Gy and 0-30 Gy, only the coefficient of $D 2$ was significant $(P<0.001)$, while both $D^{2}$ and $T$ turned significant $(P<0.001)$ at $0-40 \mathrm{~Gy}$. For the entire range of $0-50 \mathrm{~Gy}$, all the coefficients of $D, D^{2}$ and $T$ showed significance, leading to an estimate of 26 Gy for $a_{1} / a_{2}$ and 0.96 Gy/day for $a_{3} / a_{1}$. CONCLUSIONS: As with $\alpha / \beta$ and $\gamma / \alpha$ of postirradiation cell survival curves, $a_{1} / a_{2}$ and $a_{3} / a_{1}$ represents the cumulative effect of various radiobiological factors influencing clinical regression of tumor during the course of EXTRT. The dynamic changes in the coefficients of D, $\mathrm{D}^{2}$ and $\mathrm{T}$, indicate their relative importance during various phases of EXTRT.
\end{abstract}

Key words: Cervical cancer, Radiotherapy, Linear-quadratic, Alpha/beta, Time factor

\section{Introduction}

Linear-quadratic (L-Q) model has provided a satisfactory mathematical description to the mechanism of radiation induced cell kill.[1] The ratio of linear $(\alpha)$ and quadratic $(\beta)$ components of cell kill $-\alpha / \beta$, have been used to design various therapeutic strategies. ${ }^{[1-4]}$ Values of $\alpha / \beta$, especially for tumor, can be best regarded as an extension of experimentally derived in vivo or in vitro estimates. Clinical estimates of $\alpha / \beta$ are usually carried out through Fe plots between reciprocal of isoeffective dose (D) and dose per fraction (d) or logistic-dose response model from fractionated radiotherapy where the coefficients of $\mathrm{D}$ and $\mathrm{Dd}$, are considered to play a role similar to $\alpha$ and $\beta .^{[5]}$ Although the respective coefficients of D and Dd are not the true estimates of $\alpha$ and $\beta$ but their ratios continues to be preserved as estimates of $\alpha / \beta .^{[6]}$ However, in both the situations, groups of patients need to be irradiated to different dose-fractionation schedule to obtain isoeffects for specific end points which could be unethical in most clinical situations. 
Tumor regression during clinical fractionated radiotherapy can be regarded as a reflection of the conglomeration of the various radiobiological events. External radiotherapy (EXTRT) being one of the important prognosticators of long term loco-regional disease control in cancer cervix, patterns of tumor regression during the course of EXTRT assumes special significance. ${ }^{[7-9]}$

The present study has been carried out to estimate the tumor regression parameters and time factor from doseresponse relationship in patients of cancer cervix undergoing EXTRT to interpret the curvilinear L-Q curves as obtained from in vivo and in vitro studies.

\section{Materials and methods}

Seventy-seven patients of carcinoma of the cervix were selected from the database of cervical cancer treated at our institution from January 1996 to June 2001. Ethical clearance for this retrospective study was not required as the patients were subjected to a standard treatment as per the Department's policy, and the data was obtained from the review of their treatment records. All patient records maintained in our departmental data base were sorted based on the diagnosis and the years of the study. The data was retrieved by all the authors, individual files reviewed, parameters entered and taken up for systematic analysis. Out of the database, only those patients of cancer cervix in whom the treatment was delivered as per the timedose-fractionation schedule of teletherapy stated below and those in which the tumor sizes and their weekly assessment were documented were included for this analysis.

Before the start of therapy, patients were subjected to routine clinical, hematological, biochemical and radiological investigations and staged clinically as per FIGO staging guidelines. Only those patients treated with radical radiotherapy to an EXTRT dose of 50 Gy at 2 Gy per fraction with 5 fractions per week followed by intracavitary brachytherapy were considered for this analysis. Teletherapy was delivered by either telecobalt (Theratron 780C, AECL, Canada) or $6 \mathrm{MV} / 10 \mathrm{MV}$ photons (ML 20DX, Mitsubishi Corporation, Japan). Following 2 weeks of EXTRT, all these patients received high dose rate intracavitary brachytherapy of 18 Gy in 3 fractions at weekly intervals to point A (Microselectron HDR, Nucletron, The Netherlands or Ralstron 20B, Shimadzu Corporation, Japan). In all patients, periodic tumor responses at corresponding doses were available during the course of EXTRT. The details of treatment and response assessments have been described in a recent publication. ${ }^{[8]}$ Loco-regional response at the primary and parametria were recorded as percentage regression from the pretreatment size. These were based on clinical evaluation namely, per speculum, per vaginum and rectovaginal examinations carried out during weekly monitoring of patients during the course of treatment. Even though, this forms a retrospective collection of cases, these patients had been part of other prospective studies, where weekly recording of tumor regression was mandatory. Radiological assessment of response using contrast enhanced computed tomography (CECT) or magnetic resonance imaging (MRI) were not a part of any of the prospective studies, as subjecting patients to weekly imaging studies during the course of EXTRT was not practically feasible. Thus, even though imaging assessment using CECT or MRI could have refined the quantum of tumor regression, as this was not practically possible for all patients due to waiting times on CT / MRI machine and cost implications, clinical regression was uniformly advocated for all cases.

The residual gross tumor at various dose intervals was expressed in terms of residual fraction (RF) of the pretreatment tumor. Thus, starting with a RF of $\mathrm{l}$, at commencement of radiation, RF was recorded at subsequent EXTRT doses and expressed as fraction of the residual disease. The observed RF was plotted along the Y-axis against the corresponding cumulative EXTRT doses in X-axis. The scatter plots were fitted using quadratic fit.

\section{Statistical analysis}

Step wise forward linear regression for RF with EXTRT dose, was carried out as per the model, $\mathrm{RF}=\mathrm{c}+$ $a_{1}$ nd $+a_{2} n^{2}-a_{3} T$, with $c$ as constant; $n$, number of fractions; $\mathrm{d}$, dose per fraction and $\mathrm{T}$, the corresponding treatment time. Variables with probability of $\mathrm{F}$ equal to 0.05 were entered into the model and removed at 0.10. Only variables found significant at $p<0.05$ were considered for further estimations. However, in view of the poor fit with the above expression, regression was repeated using dose $\mathrm{D},(\mathrm{D}=\mathrm{nd}), \mathrm{D}^{2}$ and $\mathrm{T}$ as per the model, $\mathrm{RF}=\mathrm{c}+\mathrm{a}_{1} \mathrm{D}+\mathrm{a}_{2} \mathrm{D}^{2}-\mathrm{a}_{3} \mathrm{~T}$. As mentioned earlier, the coefficients $a_{1}, a_{2}$ and $a_{3}$ were assumed to play a role similar to coefficients $\alpha, \beta$ and $\gamma$ of the L-Q dose-effect relationship. The coefficients $-a_{1}, a_{2}$ and $a_{3}$ were therefore not the actual estimates of $\alpha, \beta$ and $\gamma$ respectively, but the ratios $a_{1} / a_{2}$ and $a_{3} / a_{1}$ could be considered to represent $\alpha / \beta$ and time factor $(\gamma / \alpha)$ respectively. ${ }^{[6]}$

The cumulative EXTRT dose range of 50 Gy was 
divided into different segments of increments of 10 Gy each i.e., 0-10 Gy, 0-20 Gy, 0-30 Gy, 0-40 Gy and 050 Gy over which the cumulative RF was evaluated. Linear regression of RF against the corresponding cumulative EXTRT dose and treatment time were carried out to examine if there were changes in the coefficients of the total dose $\mathrm{D}, \mathrm{D}^{2}$ and $\mathrm{T}$ at these dose intervals. The regression model $\mathrm{r}^{2}$, its significance and the $95 \%$ confidence intervals of the various coefficients were computed. Only those models with $\mathrm{r}^{2}$ of at least 0.5 and only those coefficients which were significant were considered for further analysis and interpretation which included estimation of $a_{1} / a_{2}$ and $a_{3} / a_{1}$ ratios. All the statistical calculations were performed using SPSS software package for windows, version 9.0 (SPSS Inc. Chicago, IL, USA).

\section{Results}

The detail demographic profiles of the patients are summarized in Table 1 with majority of patients in stages II and III. All patients had received the planned dose of 50 Gy of EXTRT followed by 18 Gy of intracavitary brachytherapy. The overall treatment time for EXTRT ranged from 33 to 52 days (median: 37 days). At the completion of teletherapy, 40 patients (51.9\%) had no gross primary loco-regional tumor and following one month of completion of intracavitary brachytherapy, $53(68.8 \%)$ patients had complete locoregional clearance of their pelvic disease.

The response fraction and corresponding EXTRT doseresponse curve showed a typical curvilinear plot on a linear scale and was fitted using a quadratic fit $\left(\mathrm{R}^{2}=\right.$
Table 1: Patient demography (Total: 77)

\begin{tabular}{|c|c|}
\hline Parameters & Distribution \\
\hline Age (years): (mean $\left.\pm \mathrm{SD}^{*}\right)$ & $50.2 \pm 10.1$ \\
\hline \multicolumn{2}{|l|}{ FIGO stage: Nos. (\%) } \\
\hline IB & $7(9.1)$ \\
\hline$\| \mathrm{A}$ & $6(7.7)$ \\
\hline IIB & $33(43)$ \\
\hline IIIA & $1(1.3)$ \\
\hline IIIB & $29(37.6)$ \\
\hline IVA & $1(1.3)$ \\
\hline \multicolumn{2}{|l|}{ Gross features: Nos. (\%) } \\
\hline Proliferative & $20(26)$ \\
\hline Ulceroproliferative & $45(58.4)$ \\
\hline Infiltrative & $12(15.6)$ \\
\hline \multicolumn{2}{|l|}{ Histology: Nos. (\%) } \\
\hline Squamous cell carcinoma & $75(97.4)$ \\
\hline Adenocarcinoma & $2(2.6)$ \\
\hline Pretreatment hemoglobin (gm/\%): (mean $\left.\pm \mathrm{SD}^{*}\right)$ & $10.4 \pm 1.6$ \\
\hline Teletherapy $\mathrm{OTT}^{\dagger}$ (days): (mean \pm SD*) & $38.4 \pm 3.8$ \\
\hline
\end{tabular}

0.838) (Figure la). On plotting the same on a loglinear scale, the shape of the curve had a strong resemblance to the classic curvilinear plots of the cell survival curves. This included an initial slope followed by shoulder and a terminal straight-line $\left(\mathrm{R}^{2}=0.739\right)$ (Figure lb).

From the entire 77 patients who had received 50 Gy of teletherapy, a step wise forward linear regression for RF was computed initially using "nd", "nd2" and T using the expression $\mathrm{RF}=\mathrm{c}+\mathrm{a}_{1}(\mathrm{nd})+\mathrm{a}_{2}\left(\mathrm{nd}^{2}\right)-\mathrm{a}_{3} \mathrm{~T}$. This failed to provide significant coefficients for "nd",

Table 2: Estimates various coefficients pertaining to the two models (a) $R F=$ constant $+a_{1}(n d)+a_{2}$ $\left(n^{2}\right)-a_{3} T$ and (b) RF = constant $+a_{1}(D)+a_{2}\left(D^{2}\right)-a_{3} T$ where, RF: response fraction with teletherapy, $\mathrm{n}$ : number of fractions, $\mathrm{d}$ : dose per fraction, $\mathrm{T}$ : external radiotherapy treatment time in days and $\mathrm{D}$ : total dose $(D=n d)$.

\begin{tabular}{|c|c|c|c|c|c|c|}
\hline \multirow[t]{2}{*}{ Variable } & \multirow[t]{2}{*}{ Coefficient } & \multicolumn{2}{|c|}{$95 \%$ C.I* } & \multirow[t]{2}{*}{$\mathrm{p}$ value } & \multirow[t]{2}{*}{$a_{1} / a_{2}$} & \multirow[t]{2}{*}{$a_{3} / a_{1}$} \\
\hline & & Lower & Upper & & & \\
\hline \multicolumn{7}{|c|}{ (a) For model : RF $=$ Constant $+a_{1}(n d)+a_{2}\left(n d^{2}\right)-a_{3} T$; (model $\left.r^{2}=0.825, p<0.001, d f=420\right)$} \\
\hline Constant & 1.071 & 1.047 & 1.095 & $<0.001$ & - & - \\
\hline nd & - & - & - & $\mathrm{ns}^{\dagger}$ & & \\
\hline $\mathrm{nd}^{2}$ & -0.0066 & -0.009 & -0.005 & $<0.001$ & & \\
\hline $\mathrm{T}$ & 0.0052 & 0.001 & 0.010 & 0.030 & & \\
\hline \multicolumn{7}{|c|}{ (b) For model : RF $=$ Constant $+a_{1}(D)+a_{2}\left(D^{2}\right)-a_{3} T$; $\left(\right.$ model $\left.r^{2}=0.840, p<0.001, d f=420\right)$} \\
\hline Constant & 1.020 & 0.992 & 1.047 & $<0.001$ & 26.00 & 0.96 \\
\hline $\mathrm{D}$ & -0.0052 & -0.010 & -0.001 & 0.019 & & \\
\hline $\mathrm{D}^{2}$ & -0.0002 & 0.000 & 0.000 & $<0.001$ & & \\
\hline$T$ & 0.0050 & 0.001 & 0.010 & 0.029 & & \\
\hline
\end{tabular}

${ }^{*} \mathrm{Cl}$ : confidence interval; ${ }^{\dagger} \mathrm{ns}$ : not significant; df: degrees of freedom 


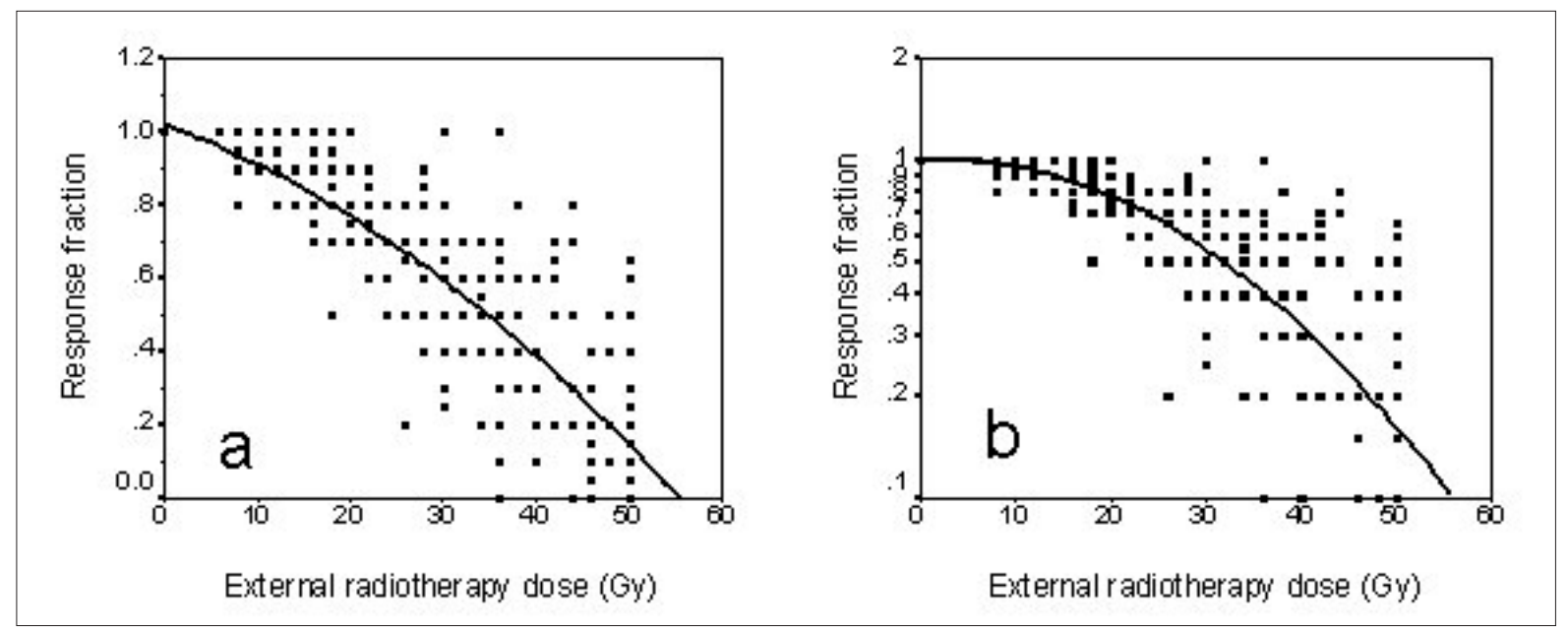

Figure 1: Response fraction versus cumulative external radiotherapy dose with quadratic curve fits plotted on (a) linear scale $\left(R^{2}=0.838\right)$ and $(b)$ log-linear scale $\left(R^{2}=0.739\right)$

thereby any further estimates for $a_{1} / a_{2}$ and $a_{3} / a_{1}$, could not be carried out (Table 2). Substituting $\mathrm{D}^{2}$ in place of $\mathrm{nd}^{2}$ in the expression $\mathrm{RF}=\mathrm{c}+\mathrm{a}_{1} \mathrm{D}+\mathrm{a}_{2} \mathrm{D}^{2}-\mathrm{a}_{3} \mathrm{~T}$, estimations were repeated and this yielded coefficients which were significant for $\mathrm{D}(\mathrm{P}=0.019), \mathrm{D}^{2}(\mathrm{P}<$ $0.001)$ and $\mathrm{T}(\mathrm{P}=0.029)$. Thus, $\mathrm{a}_{1} / \mathrm{a}_{2}$ and $\mathrm{a}_{3} / \mathrm{a}_{1}$ were estimated at 26 Gy and 0.96 Gy/day respectively (Table 2).
The cumulative dose range of 50 Gy were divided into different segments of increments of 10 Gy each i.e., 010 Gy, 0-20 Gy, 0-30 Gy, 0-40 Gy and 0-50 Gy. The regression models for $\mathrm{RF}$ at these dose intervals were considered only if the model $\mathrm{R}^{2}$ was at least 0.5 . As stated, the regression coefficients for $\mathrm{D}, \mathrm{D}^{2}$ and $\mathrm{T}$ at each of these intervals were considered only if these were significant at $\mathrm{p}<0.05$. As evident from Table 3,

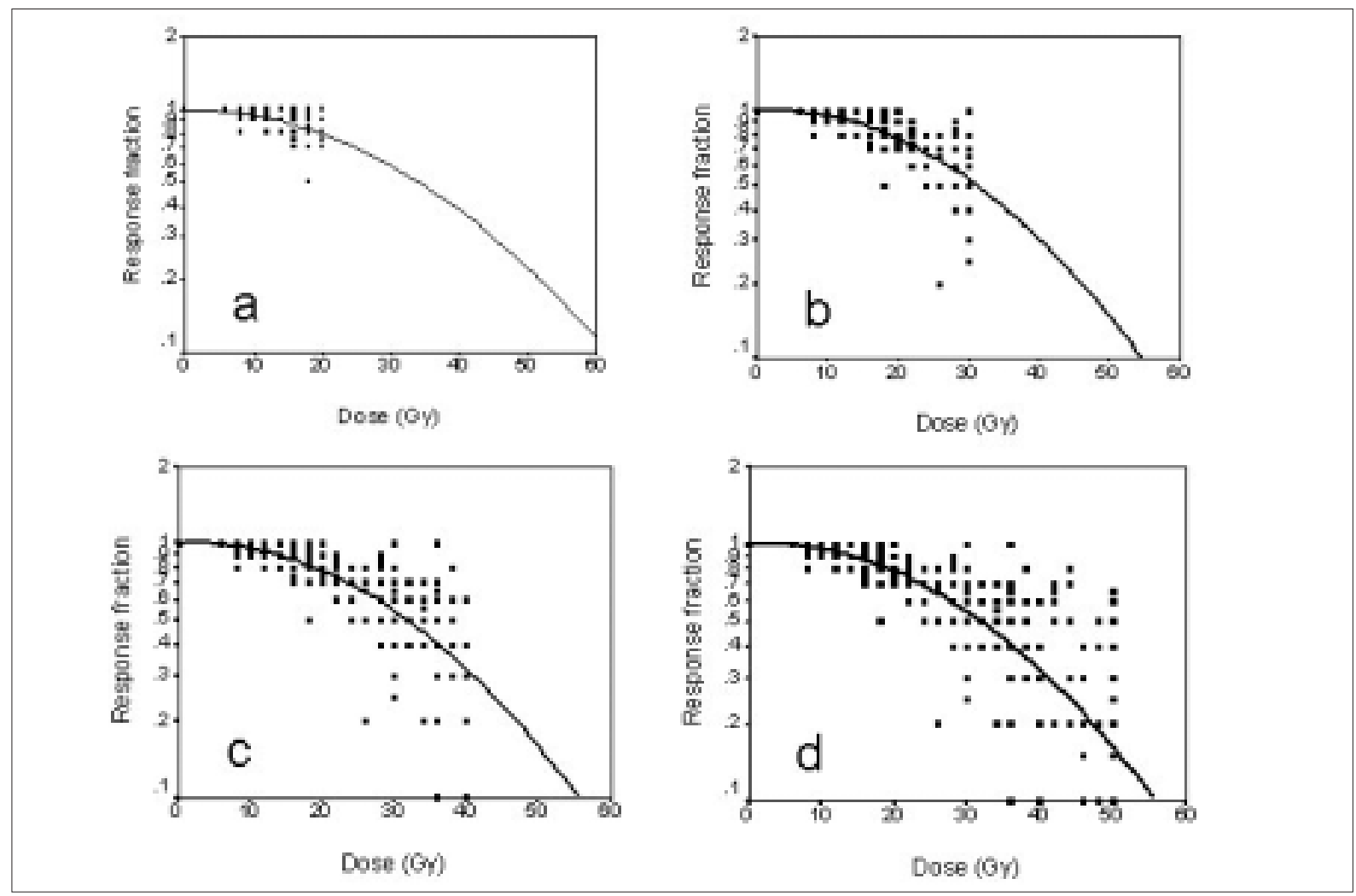

Figure 2: Response fraction versus cumulative external radiotherapy dose with quadratic curve fits at dose intervals on a loglinear scale (a) 0-20 Gy $\left(R^{2}=0.548\right)$, (b) 0-30 Gy $\left(R^{2}=0.638\right)$, (c) 0-40 Gy $\left(R^{2}=0.705\right)$ and (d) 0-50 Gy $\left(R^{2}=0.739\right)$ 
the model $\mathrm{R}^{2}$ for dose interval 0-10 Gy was unsatisfactory at 0.258 , while the models for the remaining dose intervals were beyond 0.5 . It was apparent from the models for different dose levels that $\mathrm{D}^{2}$ had an impact for all dose levels beyond 10 Gy (P $<0.001)$. The EXTRT treatment time influenced RF for dose level beyond 30 Gy $(\mathrm{P}<0.001$ for dose interval $0-40 \mathrm{~Gy}$ ) while for the entire range of $50 \mathrm{~Gy}$, all the coefficients of $\mathrm{D}, \mathrm{D}^{2}$ and $\mathrm{T}$ showed significant influence $\left(\mathrm{P}=0.019\right.$ for $\mathrm{D}, \mathrm{P}<0.001$ for $\mathrm{D}^{2}$ and $\mathrm{P}$ $=0.029$ for $\mathrm{T}$ ) (Table 3, Figure 2).

\section{Discussion}

The L-Q model, based on in vivo and in vitro studies has inherent limitations of its use for doses beyond 8 10Gy due to the continuous bending shape of the cell survival curve at higher doses. It is assumed that the effect on cell survival for each of the multiple fractions would be identical and thus L-Q model could be regarded as a low dose approximation to equations that become straight exponentials at higher doses. ${ }^{[1]}$ Estimates of $\alpha / \beta$ are the uncertain parameters used in L-Q model and the application of applying L-Q model for multi-fractional studies, is based on the assumption that every equal radiation fraction will have the same biological effect on the target, independent of its position in the series. ${ }^{[1,5]}$ This led to the expression for total effect, $\mathrm{E}$ represented with time factor as $\mathrm{E}=$ and $+\beta \mathrm{nd}^{2}-\gamma \mathrm{T}$.

The observation that clinical RF could not be satisfactorily fitted using the parameters "nd" and " $\mathrm{d}^{2}$ " indicates that for fractionated clinical radiotherapy, the effect of each fraction of dose on the RF may not be equal. This is in contrast to the basic assumption of the L-Q model for fractionated radiotherapy. On the contrary, it appeared that RF was a second order

Table 3: Estimates of various coefficients using the model, RF $=$ constant $+a_{1}(D)+a_{2}\left(D^{2}\right)-a_{3} T$ where, RF: response fraction, D: total teletherapy dose and T: teletherapy treatment time for various cumulative dose intervals.

\begin{tabular}{|c|c|c|c|c|c|c|}
\hline \multirow[t]{2}{*}{ Variable } & \multirow[t]{2}{*}{ Coefficient } & \multicolumn{2}{|c|}{$95 \%$ C.I ${ }^{*}$} & \multirow[t]{2}{*}{$\mathrm{p}$ value } & \multirow[t]{2}{*}{$a_{1} / a_{2}$} & \multirow[t]{2}{*}{$a_{3} / a_{1}$} \\
\hline & & Lower & Upper & & & \\
\hline \multicolumn{7}{|c|}{ (a) For dose interval, 0 - $10 \mathrm{~Gy}$; (model $r^{2}=0.258, p<0.001$, $d f=117$ ) } \\
\hline Constant & 0.999 & 0.993 & 1.006 & $<0.001$ & - & - \\
\hline D & - & - & - & $\mathrm{ns}^{\dagger}$ & & \\
\hline $\mathrm{D}^{2}$ & - & - & - & $\mathrm{ns}^{\dagger}$ & & \\
\hline $\mathrm{T}$ & 0.0053 & 0.004 & 0.007 & $<0.001$ & & \\
\hline \multicolumn{7}{|c|}{ (b) For dose interval, $0-20 \mathrm{~Gy} ;\left(\right.$ model $\left.r^{2}=0.583, p<0.001, d f=183\right)$} \\
\hline Constant & 1.000 & 0.998 & 1.012 & $<0.001$ & - & - \\
\hline $\mathrm{D}$ & - & - & - & $\mathrm{ns}^{\dagger}$ & & \\
\hline$D^{2}$ & -0.0005 & -0.001 & 0.000 & $<0.001$ & & \\
\hline $\mathrm{T}$ & - & - & - & $\mathrm{ns}^{\dagger}$ & & \\
\hline \multicolumn{7}{|c|}{ (c) For dose interval, $0-30 \mathrm{~Gy}$; (model $\left.r^{2}=0.728, p<0.001, d f=254\right)$} \\
\hline Constant & 0.999 & 0.983 & 1.015 & $<0.001$ & - & - \\
\hline $\mathrm{D}$ & - & - & - & $\mathrm{ns}^{\dagger}$ & & \\
\hline $\mathrm{D}^{2}$ & -0.0005 & -0.001 & 0.000 & $<0.001$ & & \\
\hline $\mathrm{T}$ & - & - & - & $\mathrm{ns}^{\dagger}$ & & \\
\hline \multicolumn{7}{|c|}{ (d) For dose interval, $0-40 \mathrm{~Gy} ;\left(\right.$ model $\left.r^{2}=0.796, p<0.001, d f=318\right)$} \\
\hline Constant & 1.005 & 0.983 & 1.026 & $<0.001$ & - & - \\
\hline $\mathrm{D}$ & - & - & - & $\mathrm{ns}^{\dagger}$ & & \\
\hline $\mathrm{D}^{2}$ & -0.0003 & 0.000 & 0.000 & $<0.001$ & & \\
\hline$T$ & 0.0053 & 0.002 & 0.009 & 0.001 & & \\
\hline \multicolumn{7}{|c|}{ (d) For dose interval, $0-50 \mathrm{~Gy} ;\left(\right.$ model $\left.r^{2}=0.840, p<0.001, d f=420\right)$} \\
\hline Constant & 1.020 & 0.992 & 1.047 & $<0.001$ & 26.00 & 0.96 \\
\hline $\mathrm{D}$ & -0.0052 & -0.010 & -0.001 & 0.019 & & \\
\hline $\mathrm{D}^{2}$ & -0.0002 & 0.000 & 0.000 & $<0.001$ & & \\
\hline $\mathrm{T}$ & 0.0050 & 0.001 & 0.010 & 0.029 & & \\
\hline
\end{tabular}

${ }^{*}$ C.I: confidence interval; ${ }^{\dagger} \mathrm{ns}$ : not significant; df: degrees of freedom 
function of the total dose delivered and for multifractionation schedules, it could be best represented in the form, $\mathrm{RF}=\mathrm{c}+\alpha \mathrm{D}+\beta \mathrm{D}^{2}-\gamma \mathrm{T}$.

This brings to the fundamental issue on the kinetics of the repair of damage caused by each fraction. Are these completely repaired before the next radiation dose delivered after 24 hours or are the cells likely to harbor residual damage at the time of each subsequent fraction of radiation? The repair of sublethal damage after each fraction is usually considered to be mono-exponential with a specific half-time $\left(\mathrm{T}_{1 / 2}\right)$ of around 0.2 to 4 hours, or to consist of a fast and a slow component with $\mathrm{T}_{1 / 2}$ of around $0.15-0.3$ hours and 2-3 hours respectively. ${ }^{[5,6]}$ This would ensure that most of the repair gets almost completed before the next dose of radiation, say after 24 hours. Thus based on these two basic assumptions, the cell survival curve for multiple fractions has been considered to have a negative exponential straight line with a slope similar to that of the initial slope, $\alpha$, caused by a dose per fraction, d, rather than the typical curvilinear plot on a log-linear scale. ${ }^{[1]}$

Over the years, the concept of a mono-exponential repair having a single exponential half time has been debated. ${ }^{[10]}$ The mono-exponential repair concept of a near complete repair for interfraction intervals around 6 to 8 hours has been debated. ${ }^{[1,12]}$ Fowler had proposed that the repair kinetics could be a second order whereby at the first half time $\tau$, the time constant for the unrepaired proportion would fall to $1 / 2$, but at $2 \tau$ it would fall to $1 / 3,3 \tau$ to $1 / 4$, at $4 \tau$ to $1 / 5$ and so on. This would indicate that in contrast to the repair being mono-exponential, considerable unrepaired damage exists even at 24 hours, which may get compounded with each subsequent radiotherapy fractions.

Based on the above derivations of incomplete repair of radiation induced damage during inter-fraction period, the assumption of equal effect for identical fractions of radiation dose in multifractionated radiotherapy may be questionable. This would alter the biological effect $\mathrm{E}$, proposed by the L-Q model from the expression, $\mathrm{E}=$ $\mathrm{n}\left(\alpha \mathrm{d}+\beta \mathrm{d}^{2}\right)$ to $\mathrm{E}=\alpha \mathrm{D}+\beta \mathrm{D}^{2}$. Incorporating the treatment time, $\mathrm{T}, \mathrm{E}$ would be better represented as $\mathrm{E}=$ $\alpha \mathrm{D}+\beta \mathrm{D}^{2}-\gamma \mathrm{T}$ in clinical situations. The observations from this study also demonstrate the validity of the latter expression (Tables 2 and 3).

Variation in coefficients of $\mathrm{D}, \mathrm{D}^{2}$ and $\mathrm{T}$ during the various cumulative EXTRT doses indicates their relative dominance during the course of EXTRT (Table 3). The results of our study could be interpreted as an analogy to the cell survival curves and the RF curve could be considered basically in 3 parts - an initial straight exponential fall, followed by a shoulder and then a straight line exponential fall [Figure 2]. At low doses (0-10 Gy), the linear component of dose would be expected to dominate and cause lethal damage to the DNA, but the results of our study has not been able to show this with certainty (Figure 3a). This could be due to the difficulty in quantification of the early tumor regression at doses till 10 Gy. However, with a cumulative dose of 0-20 Gy and beyond, cell kill was predominantly a function of quadratic component of cumulative EXTRT dose. This could be represented as lethal DNA damage due to two separate hits close to each other (Figure $3 \mathrm{~b}$ ). With time, as in clinical fractionated EXTRT, some of these could get repaired (Figure 3c), leading even to complete repair of the damage to the DNA (Figure $3 \mathrm{~d}$ ). Thus the impact of treatment time starts to show at around 3rd week of radiotherapy. By the 5 th week, the terminal part of the RF curve tends to become straight, possibly indicating the resurgence of the linear component of cell kill with a difference. In this situation some of the residual sublethal or potentially lethal damages caused by either of the two hits of quadratic component would need only a single hit to be inactivated (Figure $3 \mathrm{e}$ ). A similar change in time factor related to the tumor repopulation occurring after 2 weeks of EXTRT in head-and-neck cancer has been recently reported. ${ }^{[13]}$ The impact of treatment time, are usually ascribed to repopulation, especially when the trials are conducted with different treatment times and other split course RT schedules.

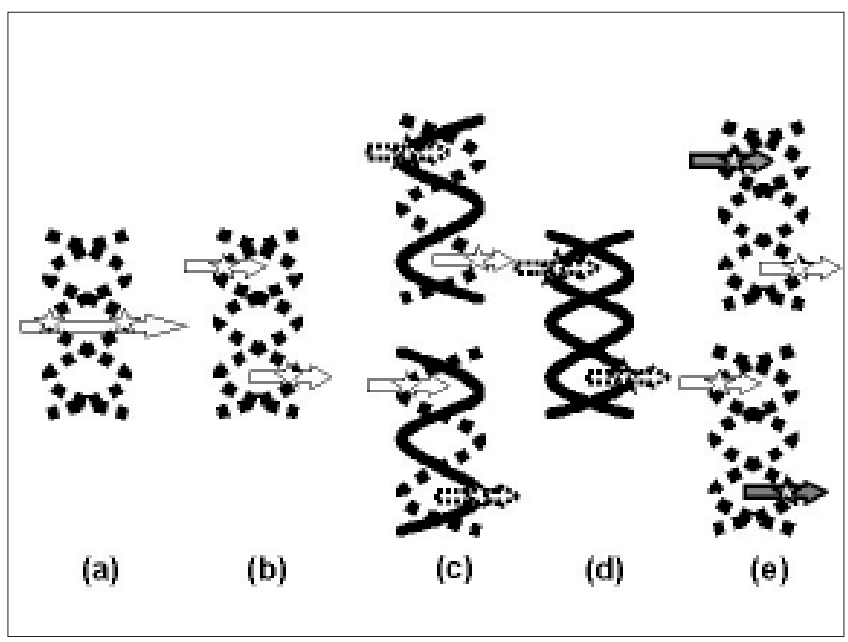

Figure 3: Schematic representation of the sequential time-course inactivation of the targets by cumulative doses of radiation as in fractionated radiotherapy; (a) inactivation of 2 targets by single hit leading to lethal damage (linear component of cell kill) (b) inactivation of 2 different targets with 2 separate hits leading to lethal damage (quadratic component of cell kill), (c) and (d) either one or both the hits could get repaired depending on the interfraction interval and time (indicated by dotted arrows) and (e) inactivation of the $2^{\text {nd }}$ target by a single hit (represented by filled arrows) from subsequent radiation leading to lethal damage (linear component) 
However, since in patients of this study, teletherapy was executed without any gap or changing time periods, repair kinetics could be a major contributory factor.

The population of shrinking tumors under the influence of reoxygenation, repopulation, tumor and tissue debris etc. are not expected to behave in a manner similar to cell survival cures from in vitro conditions. Thus, the clinical estimates of regression parameters and time factor for carcinoma of the cervix would not be expected to be identical to those of $\alpha / \beta$ and $\gamma / \alpha$ of that obtained through cell survival studies. The estimated $a_{1} /$ $a_{2}$ and $a_{3} / a_{1}$ represent the complex radiobiological phenomena taking place during fractionated radiotherapy incorporating combined influence of cell loss, changing tumor kinetics, clonogen doubling, repair, reoxygenation, blood flow and clearance of the dead and necrotic tissue / debris and thus could be more appropriate in clinical radiotherapy. ${ }^{[1,14-21]}$

Radiobiological alterations during the course of fractioned radiotherapy are a complex interplay of the " $4 \mathrm{Rs}$ " of radiobiology and attempts to represent them in L-Q equation would not only make the L-Q model lose its innocence, but also introduce several parameters with uncertainty in their estimates. ${ }^{[14,22-24]}$ This study has tried to represent estimate $\alpha / \beta$ in cervical tumors from actual dose-response relations. To the best of our knowledge, the only estimate of $\gamma / \alpha$ available in literature for cancer cervix has been reported to be more than 13.9 Gy. ${ }^{[2]}$

The estimates derived in this study could be applicable to cervical cancer treated with teletherapy using 2 Gy per fractions over a 5 week period with week end gaps. Extrapolating these to cervical tumours treated with different fractionation schedules may not be appropriate since the dose-response curves could be different for different dose per fractions. The values obtained by this study indicate that it may not be always proper to calculate biological equivalent doses for various dose fractionation studies by taking a standard $\alpha / \beta$ value of $10 \mathrm{~Gy}$ and a time factor of $0.60 \mathrm{~Gy} /$ day in all cases. Inherent limitations of these to represent the complex radiobiological phenomena during fractionated radiotherapy should always be kept in mind. Thus, mathematical models used to represent complex biological phenomena should be based on careful clinical observation to guide treatment. ${ }^{[25]}$

\section{References}

1. Fowler JF. The linear-quadratic formula and progress in fractionated radiotherapy. Br J Radiol 1989;62:679-94.

2. Thames HD, Bentzen SM, Turesson I, Overgaard M, van den Bogaert W. Time-dose factors in radiotherapy: a review of the human data. Radiother Oncol 1990;19:219-35.

3. Chougule A. Linear quadratic model compared with TDF and TSD concepts for malignancy of cervix uteri treated with twice daily fractionated schedules. Strahlenther Onkol 1994;170:30-5.

4. Sood B, Garg M, Avadhani J, Gorla G, Malhotra H, Guha C, et al. Predictive value of linear-quadratic model in the treatment of cervical cancer using high-dose-rate brachytherapy. Int J Radiat Oncol Biol Phys 2002;54:1377-87.

5. Joiner MC, van der Kogel AJ. The linear-quadratic approach to fractionation and calculation of isoeffect relationships. In: Basic clinical radiobiology, 2nd edn. Steel GG, editor. London: Arnold; 1997. p. 106-22.

6. Bentzen SM. Dose-response relationships in radiotherapy. In: Basic clinical radiobiology, 2nd edn. Steel GG, editor. London: Arnold; 1997. p. 78-86.

7. Hong JH, Chen MS, Lin FJ, Tang SG. Prognostic assessment of tumor regression after external irradiation for cervical cancer. Int J Radiat Oncol Biol Phys 1992;22:913-7.

8. Datta NR, Rajkumar A, Basu R. Tumor regression dynamics with external radiotherapy in cancer cervix and its implications. Ind J Cancer in press; 2004.

9. Chen SW, Liang JA, Yang SN, Ko HL, Lin FJ. The adverse effect of treatment prolongation in cervical cancer by high-dose-rate intracavitary brachytherapy. Radiother Oncol 2003;67:69-76.

10. Dale RG, Fowler JF, Jones B. A new incomplete-repair model based on a "reciprocal-time" pattern of sublethal damage repair. Acta Oncol 1999;38:919-29.

11. Fowler JF. Clinical implications of hyperbolic (reciprocal straight line) repair of sublethal radiation damage. In: Progress in RadioOncology VI, Bolgna. Kogelink HD, Sedlmayer E, editors. Italy: Monduzzi Editore; 1998. p. 471-9.

12. Fowler JF. Is repair of damage from ionizing radiation secondorder rather than first order? A simpler explanation of apparently multi-exponential repair. Radiat Res 1999;152:124-36.

13. Tarnawski R, Fowler J, Skladowski K, Swierniak A, Suwinski R, Maciejewski B, et al. How fast is repopulation of tumor cells during treatment gap? Int J Radiat Oncol Biol Phys 2002;54:229-36.

14. Jones B, Dale RG. Mathematical models of tumor and normal tissue response. Acta Oncol 1999;38:883-9.

15. Durand RE, Aquino-Parsons $\mathrm{C}$. Predicting response to treatment in human cancers of the uterine cervix: sequential biopsies during external beam radiotherapy. Int J Radiat Oncol Biol Phys 2004;58:555-60.

16. Travis EL, Tucker SL. Isoeffect models and fractionated radiation therapy. Int J Radiat Oncol Biol Phys 1987;13:283-7.

17. Zaider M, Wuu CS, Minerbo GN. The combined effects of sublethal damage repair, cellular repopulation and redistribution in the mitotic cycle. I. Survival probabilities after exposure to radiation. Radiat Res 1996;145:457-66.

18. Hahnfeldt P, Hlatky L. Resensitization due to redistribution of cells in the phases of the cell cycle during arbitrary radiation protocols. Radiat Res 1996; 145:134-43.

19. Wouters BG, Brown JM. Cells at intermediate oxygen levels can be more important than the "hypoxic fraction" in determining tumor response to fractionated radiotherapy. Radiat Res 1997; 147:541-50.

20. Jones B, Dale RG. Cell loss factors and the linear-quadratic model. Radiother Oncol 1995;37:136-9.

21. Brenner DJ, Hlatky LR, Hahnfeldt PJ, Hall EJ, Sachs RK. A convenient extension of the linear-quadratic model to include redistribution and reoxygenation. Int J Radiat Oncol Biol Phys 1995;32:379-90.

22. Wein LM, Cohen JE, Wu JT. Dynamic optimization of a linear-quadratic model with incomplete repair and volume-dependent sensitiv- 
ity and repopulation. Int J Radiat Oncol Biol Phys 2000;47:107383.

23. Bentzen SM, Ruifrok AC, Thames HD. Repair capacity and kinetics for human mucosa and epithelial tumors in head and neck: clinical data on the effect of changing the time interval between multiple fractions per day in radiotherapy. Radiother Oncol 1996;38:89-101.
24. Lyng H, Sundfor K, Rofstad EK. Changes in tumor oxygen tension during radiotherapy of uterine cervical cancer: relationships to changes in vascular density, cell density and frequency of mitosis and apoptosis. Int J Radiat Oncol Biol Phys 2000;46:935-46.

25. Coleman $\mathrm{CN}$. International conference on translational research ICTR 2003 conference summary: marshalling resources in a complex time. Int J Radiat Oncol Biol Phys 2004;58:307-19. 